\title{
Self-Regulated Learning Strategies Applied to Undergraduate, Graduate and Specialization Students from Civil Engineering
}

\author{
http://dx.doi.org/10.3991/ijep.v3iS2.2421 \\ J. C. Redaelli, O. F. Lima Jr \\ Universidade Estadual de Campinas, Campinas, Brazil
}

\begin{abstract}
The current demand for civil engineering work requires new skills and knowledge and calls for new and effective learning methods. This paper shows self-regulated learning strategies applied to undergraduate, graduate and specialization students from Civil Engineering in a Brazilian University. A Scale of Evaluation of Learning Strategies was administered with a view to identifying students' cognitive, metacognitive and dysfunctional learning strategies.
\end{abstract}

Index Terms-Student Performance, Self-Study, Teaching Methods

\section{INTRODUCTION}

The current demand for civil engineering work call for more effective methods of teaching and learning. Several articles have reported learning experiences in engineering courses, comprised of active learning, problem based learning, constructive alignment, and collaborative learning (see [1], [2], [3] and [4] respectively).

This study deals with a new learning approach. It aims to investigate the effects on the students, of selfregulated learning strategies, applied in classrooms. The students were from undergraduate, graduate (master's and doctoral) and specialization courses, from Civil Engineering. The rationale for such approach was to use interventions in classroom to convey some learning strategies to the students. The interventions followed the Cyclic SelfRegulated Learning Model from social-cognitive theory [5], and were done by the researcher.

Self-Regulated Learning (SRL), the core of this project, has become a key construct in education lately. It has played an outstanding role in learning and in performance inside and outside of school [5].

The ultimate objective of this study is to investigate to what extent students know how to choose and use selfregulated learning strategies. By doing this, the students might increase their learning and performance after the interventions. Hence, they might enhance or adjust their study and learning strategies.

The strategies used and demonstrated under this model, are referred to as "Self-Regulated Learning Strategies", and will be detailed later in these pages.

The Cyclic Self-Regulated Learning Model, Figure 1, is comprised of three phases: forethought, realization control and self-reflection.

(a) forethought phase establishes the stage for learning and precedes the actions; this phase includes goal setting,

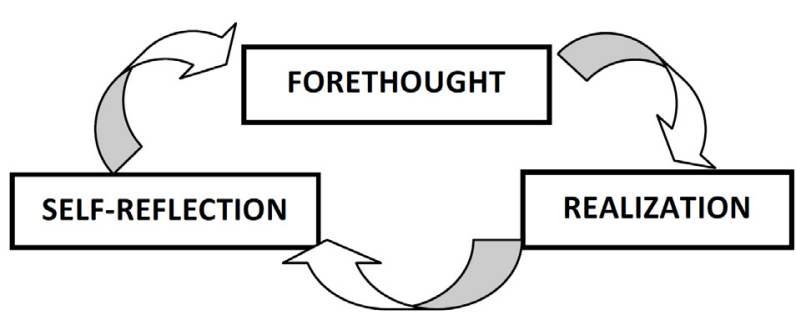

Figure 1. Cyclic Self-Regulated Learning Model

strategic planning and motivational beliefs; goal setting leads the student to decide on specific outcomes of learning; strategic planning leads the student to select a strategy to optimize the performance during learning attempts; and lastly motivational beliefs conduct the student to outcome expectation, intrinsic interest, goal orientation and self-efficacy (SE).

$\mathrm{SE}$ is the motivational process and plays a key role in the student's learning. It is an important construct related to beliefs which the individual has to achieve a goal [6]. SE has explained variations in personal motivation to control someone's achievements [7]. SE has been shown to be well suitable for explaining variations in personal motivation to self-regulate one's performance [8][9]. SE beliefs are constructed from four main sources: 1) enactive mastery experiences; 2) vicarious experiences; 3) verbal persuasion and 4) physiological and affective states [8].

(b) realization control phase involves processes such as: self-control and self-observation. Self-control processes help students guide their learning. They can be divided into self-instruction, imagery, and attention focusing and task strategies. Students use self-observation processes to monitor their performance. They have a main element called self-recording which is about taking notes such as: how long it took them to do homework; where and how they did it; and also whether the expectations had been achieved or not; and

(c) self-reflection phase occurs after the realization efforts and it evaluates the student's performance and makes adjustments; it includes self-judgment and selfreaction processes; in self-judgment processes, students have chance to self-evaluate, and to have right causal attributions for successes or failures; Students judge their successes or failures against standards, or against their classmates' performance; in self-reaction processes, student has the chance to observe levels of satisfaction with the success achieved. 
Theory and research about academic Self-Regulated Learning emerged in mid-1980s to address the question of how students could master their own learning process. SRL theory and research include social forms of learning such as modeling, guidance, and feedback from peers, coaches, and teachers. A SRL perspective shifts the focus of education from student learning abilities and environments at school or home as fixed entities to students' personally initiated strategies designed to improve learning outcomes and environments [10].

In the forethought phase of the model, the strategic planning deals with strategies used in the learning process. This study covers some Cognitive, Metacognitive and Dysfunctional strategies. Cognitive strategies help an individual achieve a particular goal (e.g., understanding a text) while metacognitive strategies ensure that the goal will be reached (e.g., seek for help). Metacognition involves active control over the cognitive processes engaged in learning (See [11]). Dysfunctional strategies are those which do not work effectively (e.g., to be distracted with something while reading or studying).

This paper aims to investigate the effects on the students, of self-regulated learning strategies, applied in classrooms. The students were from undergraduate, graduate (master's and doctoral) and specialization courses, from Civil Engineering. This was done by the researcher through interventions in classroom, based on the premises of the Cyclic Self-Regulated Learning model.

The novelty of the study lay in the use of this model to convey self-regulated learning (SRL) strategies to students of three courses from Civil Engineering.

\section{Methodology}

The participants in this study were students from Unicamp, a Brazilian University in the state of São Paulo. They were in Undergraduate, Graduate and Specialization courses, from Civil Engineering. They were administered a scale, with 49 questions about learning strategies to be responded. In the courses of 2011, the researcher performed interventions in classrooms, in each course, to convey or reinforce some learning strategies.

\section{A. Participants}

Undergraduate, graduate, and specialization students from Civil Engineering, took part in this study. The courses were respectively, "Introduction to Economics", "Modeling of Transport and Logistic Systems" and "Supply Chain and Logistic Management". The undergraduate students were in their second year. The participants were 69, 28 and 28 students respectively for each course in 2010, and 75, 16 and 31 students in 2011. There were $65 \%, 71 \%$ and $57 \%$ male students respectively in 2010, and 68\%, 62\% and 29\% male students in 2011. The average age was 19 for undergraduates in both 2010 and 2011 courses, 36 and 33 for graduates in the 2010 and 2011 courses respectively, and 28 and 29 years for specialization courses.

\section{B. A Scale of Evaluation of Learning Strategies}

The Scale of Evaluation of Learning Strategies developed by [12], aimed to identify the student's cognitive, metacognitive and dysfunctional strategies. It was administered to the selected students in 2010, at the beginning and at the end of each course. In 2011 the same scale was again administered to the same courses, at the beginning and at the end, with different groups of students. The scale is comprised of 49 questions which the students were asked to respond. It is a scale using a four-point likert type ranging from "always", "sometimes", "rarely" to "never". Each question was worth four, three, two and one scores respectively. There were 19 questions related to cognitive strategies and 23 related to metacognitive strategies. As for dysfunctional strategies, there were 7 , and the score setting was in inverse proportion to the others, that is, one score for "always", two scores for "sometimes", three scores for "rarely", and four scores for "never". As the dysfunctional strategies have an inverse score setting, those will eventually be called non dysfunctional strategies. It means, the higher the score, the less dysfunctional the student is. Here are some examples of the questions related to cognitive strategies: "Do you take notes on the texts you read or on a separate sheet?”, “Do you elaborate questions and answers about the subject being studied?"; some of the questions related to metacognitive strategies are: "Do you motivate yourself for the reading and study activities?”, "Do you control your anxiety during assessment?"; some of the questions related to dysfunctional strategies are: "Do you listen to music, or watch TV while studying or doing homework?”, "Have you ever forgotten to do your homework?”.

\section{The Interventions}

In 2010, the researcher administered the scale at the beginning and at the end of the three courses (control groups), and no intervention took place. In 2011 the researcher administered the same scale at the beginning and at the end of the same courses, with different students (experimental groups). Interventions took place in the classes and were performed to convey, to the students, aspects involving the cyclic model, mainly learning strategies. The researcher provided demonstrations of learning strategies, explained later in these pages. This experiment relied on self-reports responded by the students to the questions of the scale. The researcher used the first 20 minutes of each class of each course. The researcher drew the students' attention to some of their dysfunctional strategies, which had been gathered from their self-reports. They worked with and discussed those strategies in groups. The researcher conveyed some important concepts such as SE and SRL strategies. The students were told about the importance of being selfregulated learners and that academic success could then be under their control. The students were also told to be aware of the important link between the use of learning strategies and the success or failure in school. Three learning strategies were conveyed to the students along the interventions in the courses in 2011: note-taking during class, note-taking in reading and mind map (See [13], [14] and [15] respectively). The researcher introduced and reinforced the differences of cognitive and metacognitive strategies. The former ones are used when the student has to study a specific subject (e.g., notetaking, reading, searching for the subject in internet, and making mind maps). The latter ones are related to how the student prefers to study to achieve a goal (e.g., study in a quiet place, seek for help, study in groups, do homework, search for extra material, avoid procrastination). These learning strategies (note-taking during class, note-taking 
in reading and mind map) were demonstrated one by one by the researcher along the courses, starting from notetaking during class. The researcher provided students with homework involving the strategy in question. In the following classes the strategy was reinforced, and questions and doubts were answered. This happened similarly to the other strategies. The duration of each course was about 4 months.

For interventions, the researcher used the same procedures for the classes of all three courses and followed all phases of the model, as explained ahead.

a) Forethought Phase

The researcher explained each learning strategy through examples and demonstrations and the students were given some homework. This was equivalent to goal setting process which also served to show to the students the specific outcome expected from that homework. The use of the strategy conveyed can be considered part of the strategic planning process. The researcher tried to persuade the students that the strategy given was relevant for their learning. Doing so, the students' SE could be increased. SE is one of the motivational beliefs in the forethought phase. Direct learning and persuasion are two important sources of SE.

b) Realization Control Phase

In this phase the students are involved in their homework. They used self-control processes to maximize their learning in assigned homework. They were reminded to seek for help whenever needed to achieve the goal. The researcher was present in the following classes to be able to clarify their doubts. The students were also reminded that they should have focus on the task.

c) Self-Reflection Phase

This phase allows the students to reflect on their performance and also to make adjustments. The researcher discussed homework individually and at times collectively. This provided the students with feedback on what they did, and then they could start using self-judgment and self-reaction as they adjusted their faulty strategies. They were told to check the right attribution of their success or failure of their realization. In this phase it is normal to judge one's success against the performance of others or against earlier levels of behavior.

A cross-sectional analysis of the three courses in both years 2010 and 2011, was done using Kruskal-Wallis test. A longitudinal analysis, comparing the start and the end of the classes, for both years, 2010 and 2011, was done using the Wilcoxon test.

\section{RESULTS}

\section{A. Cross-Sectional Analysis of the three Courses}

Table I shows the cross-sectional analysis of the three courses in both years 2010 and 2011. It points students' mean score of the use of cognitive (Cog.), and non dysfunctional (NDysf.), or all (All) learning strategy, together with the standard deviations. The mean score of one strategy can be compared among Undergraduate (Underg.), Graduate (Grad.) and Specialization (Special.) courses. This can be seen at four different times: beginning and end of 2010, and beginning and end of 2011.

Only the values with significant differences ( $\mathrm{p}$-value $<=$ 0.05 ) and highly significant differences ( $p$-value $<=0.01$ ) are shown.
TABLE I.

Cross-Sectional ANALysis of The Three CoURSES

\begin{tabular}{|c|c|c|c|c|c|}
\hline Year & Strat & $\begin{array}{l}\text { Underg. } \\
\text { Mean (SD) } \\
\end{array}$ & $\begin{array}{l}\text { Grad. } \\
\text { Mean (SD) }\end{array}$ & $\begin{array}{l}\text { Special. } \\
\text { Mean (SD) }\end{array}$ & P-Value \\
\hline $\begin{array}{l}\text { Start/ } \\
2010\end{array}$ & NDysf. & 17.63 (3.13) & $19.54(3.27)$ & - & 0.012 \\
\hline $\begin{array}{l}\text { Start/ } \\
2010\end{array}$ & All & $\begin{array}{l}144.06 \\
(11.91)\end{array}$ & $\begin{array}{l}151.71 \\
(13.18)\end{array}$ & - & 0.042 \\
\hline $\begin{array}{l}\text { Start/ } \\
2011\end{array}$ & Cog. & 53.53 (6.07) & - & $57.81(4.62)$ & 0.002 \\
\hline $\begin{array}{l}\text { Start/ } \\
2011\end{array}$ & NDysf. & 17.55 & - & 19.97 (2.39) & 0.003 \\
\hline $\begin{array}{l}\text { Start/ } \\
2011\end{array}$ & All & $\begin{array}{l}143.80 \\
(12.13)\end{array}$ & - & $\begin{array}{l}152.68 \\
(10.31)\end{array}$ & $<0.001$ \\
\hline $\begin{array}{l}\text { End/ } \\
2010\end{array}$ & NDysf. & 16.48 (3.04) & - & 19.13 (1.55) & 0.003 \\
\hline $\begin{array}{l}\text { End/ } \\
2011\end{array}$ & NDysf. & 16.55 & $18.40(1.76)$ & 18.52 (3.65) & 0.009 \\
\hline
\end{tabular}

Mean: Mean score SD: Standard deviation

TABLE II.

LONGITUDINAL ANALYSIS: START/END OF EACH YEAR

\begin{tabular}{ccccl} 
Year & $\begin{array}{c}\text { Start } \\
\text { Mean (SD) }\end{array}$ & $\begin{array}{c}\text { End } \\
\text { Mean (SD) }\end{array}$ & $\begin{array}{c}\text { Strat. } \\
\text { Used }\end{array}$ & $\begin{array}{l}\text { Increase/ } \\
\text { Decrease } \\
\text { P-valuse }\end{array}$ \\
\hline Underg./ & $53.73(5.45)$ & $55.45(5.60)$ & Cog. & Incr. 0.041 \\
2010 & $17.24(3.00)$ & $16.29(3.11)$ & NDysf. & Decr. 0.004 \\
\cline { 2 - 5 } Grad./ & $74.81(6.12)$ & $71.75(9.10)$ & Metac. & Decr. 0.022 \\
2010 & $152.88(12.38)$ & $147.56(17.50)$ & All & Decr. 0.022 \\
\hline Underg./ & $72.63(7.09)$ & $70.24(6.73)$ & Metac. & Decr. 0.002 \\
2011 & $17.32(3.58)$ & $16.53(3.11)$ & NDysf. & Decr. 0.040 \\
& $143.97(12.35)$ & $140.07(11.97)$ & All & Decr. 0.002 \\
\cline { 2 - 5 } Special./ & $58.06(5.67)$ & $54.94(7.64)$ & Cog. & Decr. 0.002 \\
2011 & $74.53(7.84)$ & $70.94(6.13)$ & Metac. & Decr. 0.011 \\
Grad./ & $152.18(12.41)$ & $144.76(11.87)$ & All & Decr. $<0.001$ \\
2011 & $150.45(12.51)$ & $143.73(11.30)$ & NDysf. & Decr. 0.043 \\
\hline
\end{tabular}

Mean: Mean score SD: Standard deviation

One can see in the rows of the table that the mean score of undergraduate students are lower than the other courses, that is, graduate and specialization. The undergraduate students use more dysfunctional strategies than the others.

\section{B. Longitudinal Analysis Comparing Start-End of Each Year}

A longitudinal analysis, shown in Table II, was done by comparing the mean score at the beginning and at the end of each course in 2010 and 2011. It points students' mean score of the use of cognitive (Cog.), metacognitive (Metac.), and non dysfunctional (NDysf.), or all (All) learning strategy, together with the standard deviations. The table shows where there was an increase or a decrease in the mean score at the end of each course in each year. One can note that only the undergraduate students had the mean score of cognitive strategies increased at the end of 2010. There was also a decrease in the mean score, for those students, at the end of 2010 and 2011, of use of cognitive, metacognitive, non dysfunctional and all strategies, as shown in the Table. Only the values with significant differences (p-value $<=0.05$ ) and highly significant differences ( $\mathrm{p}$-value $<=0.01$ ) are shown.

\section{Discussion}

The cross-sectional analysis points that the mean scores of all, cognitive and non dysfunctional strategies, in graduate and specialization courses, were higher than the corresponding means scores achieved by undergraduate. 
This might have been due to broader academic background and professional experience, of the graduate and specialization students. The longitudinal analysis shows that undergraduate students used more dysfunctional strategies at the end than at the start of the courses in both 2010 and 2011. This might have been due to much lower average age (19), for 2010 and 2011, than graduate and specialization students. Furthermore, it might have also been due to low academic background and little time for practice.

Even the graduates, having high average age, academic and professional experience, the mean scores of all, and metacognitive strategies in 2010, and the non dysfunctional strategies mean score in 2011, decreased at the end of the respective courses. As for the specialization students, the mean scores of all, cognitive and metacognitive strategies decreased. This might have happened due to little practice and the strategies not being embedded in the course's syllabus.

It is desirable for the experiment that the students have more opportunities of persuasion from the researcher in classes. Persuasion is an important source of SE, the motivational aspect of forethought phase.

The resilient sense of efficacy is not created by a few successes and requires learning how to handle adversity and mastering increasingly tougher challenges through perseverant effort. New skills are unlikely to be used for long unless they prove useful when they are put into practice and students must experience sufficient success by using what they have learned to believe in themselves [8].

It is highly recommended that the teacher be the change agent, purposefully making things happen, supported by his/her belief system and self-regulatory capabilities [16].

\section{CONCLUSIONS}

This project should be further explored mainly with undergraduate students who have used more dysfunctional strategies than the graduate and specialization ones. New strategies and reinforcement of old ones should be conveyed to classes and always in a cyclical mode. The feedback should trigger new forethoughts.

Despite having the potential to be effective, this experiment has a few shortcomings: the interventions should convey only one learning strategy to only one course to ensure appropriate opportunities of use, time and a proper feedback; this intervention process was intrusive, hence we suggest that the strategies be conveyed to the students in regular classes by the teachers themselves. Concepts and strategies proposed by the model should be taught to the teachers responsible for those classes. This might set up the right value for the learning strategies. The more the teachers know about the strategies, the more the class will profit.

\section{REFERENCES}

[1] R. M. Felder, R. Brent, “Active learning”, University of West Florida, Pensacola, Florida, February 24, 2006, pp. 5-6. Available in: http://uwf.edu/cutla/workshops/Active\%20Handout.pdf. Accessed on October, 10th, 2011.

[2] T. Barret, I. M. Labhrainn, H. Fallon (eds), "Handbook of enquiry and problem-based learning”, Galway: AISHE and CELT, NUI Galway, Ireland 2005, pp. 13-25. Available in: http://www.nuigal way.ie/celt/pblbook/chapter2.pdf. Accessed in October, 2011.
[3] J. Biggs,”Aligning teaching for constructing learning”, (ed.) HEAThe Higher Education Academy-Mendeley, 2003, pp. 1-4. Available in: http://www.heacademy.ac.uk/assets/documents/resources/resourcedatabase/id477_aligning_teaching_for_constructi ng_learning.pdf. Accessed in October, 2011.

[4] P. Dillenbourg, "What do you mean by collaborative learning?”, Collaborative-learning: Cognitive and Computational Approaches, P. Dillenbourg (ed.), Oxford: Elsevier, 1999, pp.1-19. Available in: http://tecfa.unige.ch/tecfa/teaching/aei/papiers/Dillenbourg.pdf Accessed on October, 11th 2011.

[5] B. J. Zimmerman, "Developing self-fulfilling cycles of academic regulation: an analysis of exemplary instructional models”, SelfRegulated Learning From Teaching to Self-Reflective Practice, D. H. Schunk, B. J. Zimmerman, New York, London: The Guilford Press,1998, Chap. 1, p.3.

[6] T. Cleary, B. J. Zimmerman, "Self-regulation empowerment program: a school based program to enhance self-regulated and self-motivated cycles of student learning”, Psychology in the Schools, Vol.41, No. 5, New York: Wiley Periodicals Inc., 2004, p.538.

[7] M. Boekaerts, E. Cascallar, "How far have we moved towards the integration of theory and practice in self-regulation?", Springer Science+Business Media Inc., 2006, p.199. Available in: http://www.unco.edu/cebs/psychology/kevinpugh/motivation_proj ect/resources/boekaerts06.pdf. Accessed on July, 12th 2011.

[8] A. Bandura, Self-Efficacy-The Exercise of Control, New York: W. H. Freeman and Company,1997, p.136.

[9] B. J. Zimmerman, "Self-efficacy and educational development”, (Ed.). Self-efficacy in changing societies, A. Bandura, New York: Cambridge University Press, 1995, pp. 202-231.

[10] B. J. Zimmerman, "Theories of self-regulated learning and academic achievement: an overview and analysis”, Self-Regulated Learning and Academic Achievement, B. J. Zimmerman, D. H. Schunk, London: Lawrence Erlbaum Associates, Publishers, 2001, Chap. 1, p.1.

[11] J. A. Livingston, "Metacognition:An Overview”,1997. Available in: http://gse.buffalo.edu/fas/shuell/cep564/metacog.htm. Accessed in July, 2011.

[12] A. A. A. Santos, E. Boruchovitch, "Learning Strategy Scale for University Students”, unpublished, Universidade São FransciscoUniversidade Estadual de Campinas, São Paulo, Brazil.

[13] W. Pauk, "The Cornell Note-taking System”, 2001. Available in: http://lsc.sas.cornell.edu/Sidebars/Study_Skills_Resources/Study \%20Skills\%20PDFs\%20for\%20LSC\%20Website/Cornell\%20Not e-Taking\%20System.pdf. Accessed on February, 10th 2011.

[14] F. P. Robinson, "Other applications of the SQ3R method of study”, Effective Study, F. P. Robinson, Harper \& Row, Publishers, New York, Evanston, and London, Revised Edition, 1961, pp. 37-48.

[15] T. Buzan, B. Buzan, The Mind Map Book, BBC Active, Edinburgh Gate, Harlow, Essex CM@) 2JE, England, 2010, pp. 29-75.

[16] A. Bandura, Social Cognitive Theory: An Agentic Perspective, Annual Reviews Psychology, 2001, p. 2

\section{AUTHORS}

J. C. Redaelli is a Master student at Universidade Estadual de Campinas, Engenharia Civil, Arquitetura e Urbanismo, Campinas, Brazil, member of LALT-Learning Laboratory on Logistics and Transport (e-mail: jc@redaelli.com.br)

O. F. Lima Jr., is a Professor at Universidade Estadual de Campinas, Engenharia Civil, Arquitetura e Urbanismo, Campinas, Brazil, Coordinator of LALT-Learning Laboratory on Logistics and Transport (e-mail: oflimaj@fec.unicamp.br)

This article is an extended and modified version of a paper presented at the International Conference on Engineering Pedagogy (IGIP2012), held 26 - 28 September 2012, in Villach, Austria. Received 2 January 2013. Published as resubmitted by the authors 27 February 2013. 